\title{
Witnessing: Virtual Conversations
}

\author{
Asale Angel-Ajani, Carolyn J. Dean and Meg McLagan
}

\begin{abstract}
This special feature presents curated excerpts from two virtual conversations that the editors (Liana Chua and Omri Grinberg) held with anthropologist and author Asale Angel-Ajani, historian Carolyn J. Dean and anthropologist and filmmaker Meg McLagan on the theme of witnessing. Beginning with the participants' reflexive discussions of how they came to work on witnessing, the conversations delve into several intertwined questions and debates. These include the politics and impacts of witnessing; the performativity of witnessing and the subjectivities involved; the evolving place and practice of witnessing in the contemporary post-truth, digitally saturated milieu; the 'dark side' and other problematics of witnessing; how different disciplines witness and represent witnessing; and the question of what scholars can do to witness or bear witness in the present.
\end{abstract}

Keywords: anthropology, history, media, politics, representations, witnesses, witnessing

\section{Witnessing: virtual conversations}

In April and May 2019, we (this issue's editors) held two virtual conversations with three scholars who have made important contributions to the study of witnessing. Asale Angel-Ajani is an anthropologist, activist and author who writes about the global carceral state and African diaspora (see, e.g., Angel-Ajani 2004). Carolyn J. Dean is a historian of Europe who has researched cultural genealogies of 'victimhood' and 'genocide', particularly in the context of the Holocaust (e.g. Dean 2019). Meg McLagan is a filmmaker and anthropologist who has studied the relationship between politics and visual culture, especially transnational circuits of human rights media (e.g. McLagan 2005). The first exchange (in italics) consisted of a circulated set of written questions and responses; this was followed by a Skype roundtable moderated by the editors (21 May 2019). What follows are curated excerpts from both conversations. 


\title{
Participants: Asale Angel-Ajani (AA), Carolyn J. Dean (CD), Meg McLagan (MM) Moderators: Liana Chua (LC), Omri Grinberg (OG)
}

\author{
Moderators: What drew you to the theme of witnessing?
}

CD: I had worked extensively on victim testimonies and was extremely frustrated by the lack of theoretical reflection by historians, who posed a dichotomy between memory and history and often questioned the usefulness of some testimonies, or used them in a restricted fashion. At the same time, literary theorists used them to explore traumatic experience with little regard for their particular historical contexts or at least for how those might have figured into testimonies. This frustration led me to consider how victim testimony had been constructed and interpreted culturally. I began to look at work on atrocity photography and 'witnessing' and found that most of it assumed that even distant spectators were referred to as 'witnesses' - secondary or third-party witnesses - and I wanted to understand how witnessing had become the moral and emotional rather than forensic testimony of third parties, which had been the case before two World Wars and the Holocaust of European Jewry rendered victims the most important witness-bearers. I also wanted to understand how witnessing had become a central moral activity and trope of Western culture and politics.

MM: Early in my career I spent a year deeply immersed in a gay and trans AfricanAmerican and Latino ball subculture in New York City as the original producer of the feature documentary Paris is Burning (1990). One of our aims was to provide a forum to get these people's stories out into a wider world in which they were invisibilized. The film's success opened up a series of complicated questions. ... An initial admiring critical reception [including from the trans community] quickly gave way to charged condemnations of a white queer filmmaker representing a black and Latino world (hooks 1992). This, in turn, was challenged by a literature on queer performativity that saw the film making a spectacle out of the normalized production of gender and offering fantastic alternatives to those norms (Butler 2011).

What all of this success, critique and counter-critique opened up for me was a far greater concern for the way that spectacle is made political. ... It stimulated my intellectual interest in understanding forms of witnessing, how to mobilize through these forms, and the architecture of politics and publicity they entailed. As a result, I enrolled in a Ph.D. programme in anthropology and film. My doctoral work focused on the relations between Tibetan refugees and their Western supporters and examined the ways in which a political movement gains visibility. ... Telling stories about oneself was not a common mode of expression in Tibet before 1959. But in their new context in exile, Tibetans were forced to define themselves vis-à-vis those around them. ... [They] had to reframe their struggle in terms that made sense according to political categories in the West at the time, such as human rights, women's rights, environmental rights, etc.

I became interested in the ways in which human rights claims are made through the idiom of suffering and tend to arrive, pre-coded, in testimonial form. Whether 
performed in private or in public, they construct a moral universe of victims and perpetrators through the production of narratives of suffering. ... I started asking myself: 'what does testimonial proffer?' after I saw a monk [who was a] former political prisoner testify at a public event in New York which ended prematurely when he became overwhelmed by emotion, and could no longer speak. He was clearly traumatized and should not have been asked to testify. My reading of the event was that his testimony provided a surplus of meaning that spilled beyond the parameters used to contextualize and produce meaning from his experiences. This excess of affect overwhelmed the communicative event; we had affect but not communication, which made his story unable to circulate, to be taken up in the same way other former political prisoners' stories had been. In a sense, it was a failed mediation.

AA: As an anthropologist who was working with incarcerated African migrants, inside prisons, with guards and police and sometimes with legal representatives, the 'theme' of witnessing was... a necessary aspect of all the surveillance and trauma of violence that I was documenting in the lives of African migrant women and that I, myself, as a Black woman was also subjected to in the field and, to some extent, in academia. The idea of 'witnessing', the promise and perils of it, was something of an urgent intellectual exercise for me as I tried to make sense of how the discipline of Anthropology would and could make room for the kind of 'communities' and people that I was working with....

Here I was, studying women, Black women, outside the US for 'crimes' of drug trafficking and insisting on viewing their experiences, their choices as a form of self-determination in the face of the devastating global economic restructuring and violent conflict. In the critical work coming out of Anthropology at the time, there was no space for the kinds of lives the women that I worked with had. There was no open reception of their experiences, only the insistence that I look at problems linked to migration, or in some cases, violent conflict in the countries they were coming from. ... I found much more nuance in writing being done by scholars who worked both critically and professionally with survivors of the Jewish Holocaust in particular. In much of that literature, I found a willingness on the part of the researcher/author to name the flaws in the work we were producing. There was no self-congratulatory posturing that, to me, still marks much of the discipline of Anthropology. Instead, these scholars of witnessing were making the case for complexity, even contradiction, in our knowledge production. They understood the many ways in which one could 'witness' and likewise, be observed.

Our Skype conversation began with the participants elaborating on their responses (above)...

CD: There is very little discussion of how bearing witness came to be a crucial cultural trope. Why do witnesses have the authority that they do? In the recent historical past - the importance of witnessing is obviously linked to ancient religious martyrdom linguistically and culturally - first-person witnesses who were victims 
had no authority because they were deemed to be lacking credibility. They were imagined to be too close to the experience to possess any objective recall or neutral investment. It took until World War II for victims in the West to be given that kind of credibility. I was really interested in those historical movements - how victims' voices became credible. These are questions [about] how bearing witness became a form of politics... Part of that was exploring who got to witness - victims, objects, observers, experts ... and those kinds of discussions are not really historicized.

AA: First it started off as a critique of some of my colleagues in anthropology. Because I specifically work around the issue of criminal justice, I always found it troubling to think through tropes of witness and testimony. We kind of bandy about these terms, especially when we're thinking through questions about human rights and the work that we do, but because I was working in a prison I found that I wasn't always very comfortable about the language of policing and testimony. ... So that's how it started off, but then [I asked:] what are the political ramifications of witnessing? Do we just leave it there, how do we carry this forward? One of the things I've been thinking about lately is returning to the literature and thinking through not just representation but also writing as it links to conversations around witnessing, and practices of writing and practices of craft, the craft of ethnography.

CD: So it's sort of a reflexive ethnography? How would you define your work in the prison as providing an opportunity to question the kind of self-criticisms that anthropologists have already engaged in?

AA: There's a multi-part answer to that question. And I think that you said this beautifully when you were talking about how people who serve as witnesses get to be deemed as holding some authority, where previously first-person witnesses did not hold that authority. For me, I was trying to think through how witnessing becomes more of a communal act of reinforcing memory: either there's not a lot that goes on with that and maybe it ... exists outside of the realms of authority but [is] just sort of affirming someone's experience. I wouldn't necessarily call my work reflexive ethnography, but I would call it engaged ethnography. 'Reflexive ethnography', as I understand it, still centres the authority of the anthropologist. I am less interested in that than trying to understand how the communities that we write about are producers of their own knowledge and creators of their own narratives. In trying to think through how listening, as an act of witness, can be represented, in trying to capture the full experiences of someone's story - that has little to do with my interpretation of events or the professional obligation to create meaning of women's everyday lives through the citations of scholars who might not have been able to hold the lives of incarcerated African women in their imagination - was really what drove me to write my book in the way that I did.

CD: One of the things you emphasize that's really interesting - and this is really a problem for historians - is the performative. Witnessing is always performative, you 
require an audience, but then how it becomes political is precisely how it becomes validating and collective, and the question is: how do you analyse that? How do you go from individual testimony to individual or collective validation of testimony in a way that is politicizing rather than simply experienced as psychological recognition? ... [How do] those individual stories become a form of politics that are not simply the expression of an apolitical evocation of humanity?

MM: For me, the thing is: how do you work between the categories, how do you translate testimony into action? And how do you get the 'take-up' - how do you prevent it from just being ineffective politically, and then what are the issues in getting that circulation to work in the right way? I think in the current moment, we have to understand the nature of each medium and which things are now being circulated. We have to have a more refined understanding of how these structures and forms of mediation work in certain ways, and which ones produce the kind of political effects in the world that we want. We're way beyond documentary film and that kind of reliance on the indexicality of the image. [So] what are these other forms if it's not about indexical forms of witnessing ... and how do you stake those claims?

LC: I wonder if what we're [also] looking at today is a redefinition of that boundary between the personal and the political, which impacts how that take-up occurs. When you think, for example, about \#MeToo on Twitter: these are intensely personal and political acts, and they're cumulatively having a political effect by forcing conversation at the levels of structures and institutions.

MM: ... Where does politics reside these days? I would be interested to look, in a year or two, at some of the scholarship on how these things play out in terms of \#MeToo. How do these things get purchase?

CD: Maybe one way to think about [it...] is: what is political? [For example] you click on [a button that says, 'Click here to stop torture'], and then you listen, you empathize, and then you give money and then you move on. So, how do we think about the politics of it? ... In the \#MeToo movement it's always been about either spectacle or not spectacle - the choice is either you make a spectacle and then you risk the criticisms that it's mob-like, it's anti-democratic; or you don't do it at all.

MM: It's too binary. ... Maybe we ... need to take a more processual approach: look at how things are constructed [and] circulate, what ... subject-positions are offered. Maybe it's a way for people to be connected to political projects they believe in, so it's an expression of their own political commitments as much as anything else. I absolutely agree about moving beyond the binary and ... tracing the kind of emanations from [witnessing events] in order to understand how things move.... [i]nstead of looking at the image. 
LC: On getting past binaries, and following Carolyn's point about witnessing being built around the category of the victim: is it possible to witness without a victim/ victimhood?

CD: ... Since witnessing is so mediated ... the victim is never just the victim. ... If you actually pay attention to how Western peoples after the war constructed their own murderousness, the witness is always a representation and a projection of non-victims onto (in this case) Jewish victims. The Holocaust survivor's wisdom was very much a projection of the audience. Most Holocaust survivors just suffered, but the projection of authority and wisdom onto them was always more about the audience than it was about actual survivors. When you say, 'can you witness without a victim?' - I think you're always doing that on some level, because witnessing the suffering of others always involves projection, regardless of how direct the testimony is.

In terms of overcoming the binary: I read through ... debates about atrocity photography, and I realized that critics imagined a kind of figure. ... I called it a counter-witness, an image that emerges out of certain left-wing takes on the problem [of how certain representations take] agency away from the people with whom we're supposed to be empathizing. What emerges in some of these criticisms is the image of a dignified witness who stares back, is defiant. It's very common, and it's very gendered too. That's just to throw that out there - to try and see how these new figures emerge. These critics had inadvertently shaped an image of a victim in the course of discussing their own responses to atrocity photos.

MM: It sounds like [the witness] moves back from an affectively oriented performance to [a form of witnessing] where the aim is to not be subsumed by a more simplistic take-up in terms of compassion. People have written a lot about this in [relation to] documentary: how do you present people in ways that allow them to maintain their dignity and humanity, and not just be reduced to a symbol of something actually not related to them aside from this one experience that they may have had?

OG: Meg, you shared with us the powerful anecdote about the Tibetan monk who shouldn't have been a witness. And this is a question [about] the ethnocentricity of witnessing - what we suppose a witness should be... So, how can we, as teachers and as scholars, avoid [reproducing] that image of a witness [ourselves, and] encourage students not to produce that image repeatedly?

MM: Yeah, that example of failed witnesses. This was an example where the performative moment failed and the witness kind of deconstructed himself in front of everyone. That sort of implosion of that moment signals the constructedness of the encounter and the purpose of it. His humanity, his suffering was actually revealed in a completely different way, not a pre-coded way, but in that moment it leaked out 
and showed through. So [we can find] ways to talk about instances where testimony fails - either fails to have an effect, or fails in the moment, and then in so doing highlights or reveals some of these processes and stakes that we're talking about in terms of staging the political, or staging the politics that we're trying to assert or advance.

CD: There's a new book, Ecologies of Witnessing (Pollin-Galay 2018), that is about this. [It's a study of] Jewish survivors in Lithuania, the United States and Israel and how their testimony changes in accord with the culture in which they have lived. [The author] went to Lithuania and asked survivors the kinds of questions that she hears asked, say, of Shoah survivors in the US, and they don't understand what she's talking about. She realizes she has to reinvent the questions because her effort to witness failed - and it was through these failures that she learned how to ask the right questions, partly to elicit answers that were much more in keeping with what they wanted to say.

Moderators: What does witnessing entail in the contemporary world - particularly given a digitally saturated, politically polarized, 'post-truth' milieu?

CD: It's hard to assess.... Social media requires a rethinking of witnessing as a new form of performance, either by victims or experts. Here, it helps to understand witnessing as a cultural activity from a historical perspective. In my view, witnessing has become an activity primarily of second-and third-party activists and has become less and more credible to a general public: less credible because it is associated with advocates and more credible because 'witnessing' is now done (once again) by experts who are not themselves victims and who are assumed to have more credibility than the victims themselves. Since credibility increasingly relies on who is listening or looking, and no longer on the 'truth' of visual images, it's unclear to me that witnessing will ever have the power it once did. But the visual is now clearly pre-eminent, and that comes with the difficulty of contextualization and the distortions and suspicions to which any visual image is now subjected. I am not entirely sure that the visual has lost its magic to convey 'truth', but its truth is highly compromised.

AA: I try to stay away from the assumption that 'witnessing' is some unique act done by a select few or that there is some inherent truth or good to the role of the witness. Witnesses have both betrayed and failed. I am most committed to acts of witnessing with small 'w's that anyone, without any special degree or knowledge can and does participate in daily. Witnesses are both appointed and involuntary. To me, witnessing is an act of both preserving and constructing memory. It is an act of listening, making space, expansion. What we will do as witnesses with stories, testimonies, observations and the silences in this moment poses a huge responsibility and one that we must be willing to share. There are so many situations that require the kind of humanizing that witnessing/testimonial can provide. I think, too, that we need to think more critically about how we understand what it means to witness. When I was growing up, as an 
African American, it was not uncommon for me to hear the men and women around me (and to later) ask it myself, 'Can I get a witness?' Meaning, can I get someone else to vouch for my humanity? Or can someone make me feel less alone in the world. There is power in acts of witnessing, of validating another's humanity. It might not rest in the hands of the so-called 'experts' but should it be? Just look at what is happening around Black Lives Matter and community responses to police violence and murder. Without the images captured on phones and shared out across social media, brutal murders and continued acts of terror against Black and Brown communities would go unseen and unacknowledged. These are powerful acts of witness that people must grapple with and not turn away from.

MM: While working on Sensible Politics (McLagan and McKee 2012) I also was making a feature-length documentary about American servicewomen who served in Iraq called Lioness. One of the things that intrigued me about military women was the fact that they confounded or scrambled some of our usual categories of left/right, gender and class. I bring it up to raise the question: what do we do with testimony that comes from different or 'bad' subjects? From perpetrators of violence, for instance, rather than victims of it. From pro-military women who believe in God as well as in their equal right to serve in combat arms jobs, such as Shannon Morgan, the main character of Lioness.

In the film, we watch Shannon, who was sent out into direct ground combat... tell the story of getting into a firefight and killing an Iraqi insurgent. As she recalls, 'in that moment I remember, I asked God, is this right? Because I don't want to go to hell someday because I killed somebody.... Later in the film we hear her talking about going to VA [US Department of Veterans Affairs] to get help when she returned home ... and felt lost. When she first went, none of the male doctors at the VA believed that she'd been in combat, that that was the source of her problems.... Like those of many veterans of the post-9/11 wars, Shannon's moral concerns had nowhere to go; they were individualized, pathologized, taken out of the collective frame and put into a PTSD frame by VA psychologists.

LC: I'm thinking about what we might call the kind of dark side of witnessing. Both of you (CD and $\mathrm{MM}$ ) pointed to the ways in which, as Asale puts it in her critique (2004), witnessing is not always this noble endeavour - it can, whether deliberately or otherwise, perpetuate violence or oppression. ... And I wonder if we're [scholars] not necessarily well equipped to deal with these less good or savoury aspects of witnessing, because we tend to want to work on the side of the marginalized. That's where a lot of the writing on witnessing has coalesced.

MM: When we started working on that film (Lioness), [the Iraq War] was very hard to talk about ... even the media were totally silenced and cowed by the Bush administration and the powers-that-be. And then the violence that these people [military personnel] perpetrated then gets individualized and pathologized and then separated from our individual responsibility. And I think that film as a form 
allows more information to be conveyed that can't be controlled. There's something about film that always escapes the container of the frame. That moment with Shannon in the woods, where she talks about killing, and then tries to indicate her feeling about her remorse ... it's [film] just a form that allows these complications [to be] revealed in a different way. I can imagine that if I were reading this account of Shannon's experience, it would have a very different effect.

LC: Can we discuss the politics and ethics of scholarly engagement in circuits of witnessing? As scholars we tend to have a highly critical, deconstructive perspective, and it's not always clear whether it's possible to transfer that perspective to real-life collaborative relationships...

MM: I certainly have at times felt glad that some of the people I was working with were not reading anything I was publishing, given the difference in terms of discourse. Many of us have written on WITNESS, a human rights NGO ... and I think that's a great example where people are very much in dialogue [with the scholarship]. It just becomes a very self-conscious acknowledged practice - we do do this, and there's no apologies, there's no problem if we're deconstructing it or seeing it, looking at it with a critical eye.

LC: But it's an interesting means-ends question. It goes back to the dark side of witnessing: at what point might we as scholars have to draw a line between what could be potentially detrimental practices and what we're looking at?

MM: Yeah, I think it's very similar ... we go through human subject reviews, we have a process of making ourselves accountable in some way. I think it's a loose thing because you could write something that would be very damaging, but my experience is that a lot of this work just doesn't circulate in that way - except maybe for these hot button issues like the Holocaust. In general, most of our writing would try to be fairly thoughtful and balanced because we actually are engaged with our subjects. For any kind of traditional anthropology where you're working with people on the ground on a daily basis, it's really an ethnographic relationship of mutual trust.

OG: There's a privilege or a certain benefit of being a historian where you [usually] don't actually have to deal with informants in the same way with the same sort of intimacy. In history, and in certain visual studies or text-based work ... in a way there's critical distancing towards witnessing where you can say certain things without having a face floating around in your head...

CD: I write about patterns of representation as they're generated historically. When we're thinking about what a witness looks like, what do we imagine? We do have a cultural idea of what a witness might be, and we have an idea of what witnesses look like, feel like, who is credible, who is not. Obviously witnessing is an ancient Jewish 
and Christian practice, and it has taken different forms and been radically refigured over time. I'm interested in how that happens and what are those representations [in the West].

MM: So it's a temporal thing - working in the present rather than in the past has different challenges.

\section{LC: Do Holocaust testimonies have afterlives?}

CD: The Holocaust was not remembered as the Holocaust until the 1960s anyway - so basically, not for fifteen years after the war. [Before that] it wasn't the Holocaust - the dead and still living were victims of fascism. Witnesses were originally resisters. Then as the Holocaust was defined as a crime against European Jewry, they were victims of the Shoah. And we now only remember it as a crime against Jews, but that's not how it was remembered initially. What I find interesting is [how Holocaust survivors are] made into 'Holocaust survivors'. Once you understand that process, the question becomes: why is the Holocaust invoked today to speak about genocides elsewhere which have no relationship to this historical event? Why is it that when nations don't act - which is almost all of the time - if you invoke the Holocaust you can make something seem more important? ... By doing a genealogy of witnessing, you can see why some events give victims a certain kind of authority over others and why those events are deemed to be paradigmatic of genocide, especially now that we have a way of understanding some kinds of violence as genocidal.

MM: Can I go back to something you [said Carolyn], in terms of Holocaust pervasiveness? It gets to be seen as a limit test - this is the bottom, this is the furthest, the most, the worst. But it does make me wonder [about] the cross-cultural dimension. You know, this is usually an English or European language public that are viewing, reading, talking, arguing [about it]. [But] ... are there comparable examples [elsewhere,] either of separate sets of images that circulate that reference a different history and does the Holocaust figure in some new way, in a conversation that we may not have access to?

LC: It's something I'm asking [in my work on orangutan conservation in Borneo], whereby the humanitarian-style witnessing practices of international conservation don't necessarily make sense to the people whose lives they're affecting. The question then becomes: what about these people? ... Those [conservation] images are calculated to produce responses in Western viewers, but they have a different effect on the ground.

CD: I think that's true. ... In Ecologies of Witnessing, there's not even a universal language to talk about the Shoah for people who were in the same place experiencing the same thing, as their experience was so mediated by where they were and 
the cultures in which they lived. So that idea of a global universal memory is of course a misnomer. ... It's a Western self-perception - it's Western people coming to terms with their own murderousness, essentially. But that's the story of Holocaust memory. On the other hand, as you said, if you talk about the Holocaust I don't know, in China - [there] the problem is Japan. The Japanese were responsible for horrific violence against the Chinese, so, Holocaust memory is obviously not a crucial frame of reference.

OG: I guess that's the point where anthropology should intervene, in identifying these ways of narration and documentation that are not within what Meg called the [model of] indexing of these experiences and how they're pre-coded.

CD: That's at the crossroads of history and anthropology. You'd have to contextualize the narratives, but also incorporate the anthropologist's more hands-on ethnographic work. ... It's not as if - as some have claimed by reference to an 'Americanized' and 'global' memory of the Holocaust - an event can simply be exported, no matter how pre-packaged [as in a Hollywood film about the Holocaust]. I think about what you wrote, Meg, in your response about Paris is Burning. It's so interesting that different communities not only have different reactions but also that reactions can become negative ones when other communities have positive ones.

MM: Yeah, and I think people in turn are reacting to their own [position].... [bell hooks] was really upset with the reception of the film in a way, [because] she felt that it was disturbing to see how audiences including Black and Latino, gay audiences were responding and identifying with it - and she felt, that's not really who we are.

LC: Which also suggests that concerns about the applicability or inapplicability of witnessing as a trope and analytical device don't just fall along cultural lines.

Moderators: What does it mean for scholars to witness and/or bear witness in the present?

AA: I think that in the United States we are now only waking up from the decades-long sleep of flattening and neutralizing language that has marked so much of the academy. I am seeing that people are much more interested in returning to forms of writing that bear witness. It's a writing that humanizes trauma and dignifies survival while critically assessing and denouncing the structures of violence, the perpetrators and the conspirators. As the illusion of stable university positions dries up, so too does the trend to write for 'tenure' or for the 'job market'. Perhaps one positive that comes out of this rupture of stability is a kind of courage on the part of scholars to share the burden of witness that we ask of our 'informants'. Meaning, that we now are seeing people be less concerned with the dated disciplinary vernacular that marks our work 'theoretical' or 'ethnographic' (and hence, not theoretical enough). 
CD: Witnessing often stands in for a politics, but it's quite unclear how witnessing is actually political unless people do something about what they hear or see. Witnessing, which is an activity of empathic identification, is not political action but can feel to the spectator as if the acknowledgement and recognition of crimes is itself an act of some sort. I would begin by questioning whether 'bearing witness' is a viable politics and how - what does it mean to bear witness beyond documenting that something happened. ... Victims have become primarily symbolic of a recent past in which genocide has become frequent, promises have been made, and most promises are never honoured because there is no international infrastructure or political will to honour them. This state of things (the limits of the International Criminal Court because of sovereignty issues, the limits of aid and so on) suggests that the power of the narrative about bearing witness has increased along with the powerlessness to address oppression and persecution.

Moderators: What, if anything, is distinctive about anthropological witnessing?

MM: Anthropologists could help combat the recalcitrant Eurocentric conceptual focus of witnessing and offer some transcultural contextualization for the concept of testimony. What might we be able to add to what we already know about the specificity of testimony as a cultural and historical genre?... Anthropologists could also help explore how affects associated with trauma and testimony can serve as the foundation for the formation of public cultures that are not contained with an institutional project, that are not linked to telling a story as a mode of declaring an identity or seeking of legal redress, but instead are related to unpredictable forms of politics.

AA: There are brave and important works that are being produced by anthropologists, works that are well researched, complex and significant in the sharing of unheard or silenced communities. And yet, many recent ethnographies have done away with narrating certain aspects of human experience in favour of illuminating and giving voice to corporate bodies and state entities - which is indeed important - and we certainly need both but at this moment, in this time of unprecedented upheaval there seems to be a great need to attend to the kinds of complexity that a critical and informed anthropological witnessing can offer.

- LC and OG thank the participants for their time, thoughtfulness and generosity.

Asale Angel-Ajani is a writer and professor of Women's and Gender Studies, Anthropology and Black Studies at City College in New York. She's the author of Strange Trade, a work of narrative nonfiction about African women drug traffickers in Italy published by Perseus Books, and the novel A Country You Can Leave, forthcoming with MCD+ Farrar, Straus and Giroux. She is completing her third book, a collection of essays entitled Friends with White People: On the Terror of Racial Intimacies.Email: aangelajani@ccny.cuny.edu. 
Carolyn J. Dean is Charles J. Stille Professor of History and French at Yale. She teaches twentieth-century European cultural and intellectual history and is the author of six books, including, most recently, Aversion and Erasure: The Fate of the Victim after the Holocaust (Cornell University Press, 2010) and The Moral Witness: Trials and Testimonies after Genocide (Cornell, 2019).

Email: carolyn.dean@yale.edu.

Meg McLagan is a filmmaker and anthropologist whose work focuses on the relationship between politics and visual culture. She has published essays on human rights, testimony, and architectures of activism, and co-edited Sensible Politics: The Visual Culture of Nongovernmental Activism (Zone Books, 2012). Materials from her doctoral research on transnational Tibet activism are housed in the C.V. Starr East Asian Library at Columbia University as part of the Meg McLagan Collection: The Tibet Movement in Exile, 1989-2003. McLagan is Visiting Professor of Professional Practice in Film Studies at Barnard College and affiliate faculty, Modern Tibetan Studies, Weatherhead East Asian Institute, Columbia University. Email: mmclagan@barnard.edu.

\section{Filmography}

Lioness. 2008. 82 min. Directed by Meg McLagan and Daria Sommers. Room 11 Productions.

Paris is Burning. 1990. 78 min. Directed by Jennie Livingston. Off White Productions.

\section{References}

Angel-Ajani, A. 2004. 'Expert Witness: Notes toward Revisiting the Politics of Listening'. Anthropology and Humanism 29: 133-144.

Butler, J. 2011. Bodies that Matter: On the Discursive Limits of 'Sex'. Abingdon: Routledge. Dean, C. J. 2019. The Moral Witness: Trials and Testimony after Genocide. Ithaca: Cornell University Press.

hooks, b. 1992. Black Looks: Race and Representation. Boston, MA: South End Press.

McLagan, M. 2005. 'Circuits of Suffering'. PoLAR: Political and Legal Anthropology Review 28: 223-239.

McLagan, M. and Y. McKee (eds). 2012. Sensible Politics: The Visual Culture of Nongovernmental Activism. New York: Zone Books.

Pollin-Galay, H. 2018. Ecologies of Witnessing: Language, Place, and Holocaust Testimony. New Haven, CT: Yale University Press. 